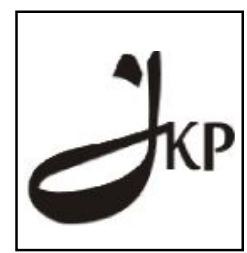

Info Artikel:

Diterima 08/01/2014

Direvisi 12/01/2014

Dipublikasikan 28/02/2014
Jurnal Konseling dan Pendidikan

ISSN Cetak: 2337-6740 - ISSN Online: 2337-6880

http://jurnal.konselingindonesia.com

Volume 2 Nomor 1, Februari , HIm 30-35

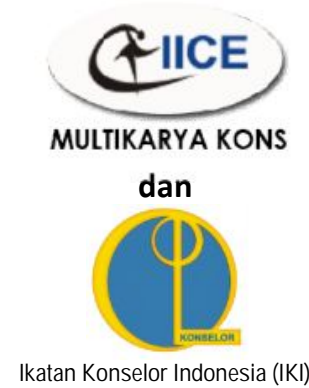

\title{
Pendapat Siswa tentang Pelaksanaan Instrumen Non-Tes
}

Melia Sutra Dewi, Indra Ibrahim

Universitas Negeri Padang

Abstract

Implementation of the non-test instrument is essential to support the guidance and counseling services in schools. Phenomenon in the field of guidance and counseling teachers less preparing/planning the implementation of the non-test instrument and there is guidance and counseling teachers who do not deliver the results to the students as well as less use of non-test instrument results. This study aims to describe students' opinions about: (1) preparation/planning, (2) the administration, (3) the delivery of results, and (4) the use of non-test instrument results. Type a descriptive study with a class XI student population numbering 178 people. Samples numbered 61 people were taken using purposive sampling technique. Data were collected using a questionnaire and analyzed by a percentage formula. The results showed that students' opinions on the implementation of the non-test instrument with respect to: (1) preparation/planning done well, (2) the administration, (3) the delivery of results, and (4) the use of non-test results is less instrument performing well.

Keyword: Opinions, Implementation of the Non-Test Instrument

Copyright (C) 2014 IICE - Multikarya Kons (Padang - Indonesia) dan IKI - Ikatan Konselor Indonesia - All Rights Reserved

Indonesian Institute for Counseling and Education (IICE) Multikarya Kons

\section{PENDAHULUAN}

Pelayanan bimbingan dan konseling merupakan salah satu komponen penting untuk pendidikan di sekolah. Bimbingan dan konseling adalah bagian dari kurikulum yang harus disiapkan guru bimbingan dan konseling kepada peserta didik. Pentingnya bimbingan dan konseling tidak terlepas dari tujuan bimbingan dan konseling itu sendiri yaitu untuk membantu perkembangan siswa se-optimal mungkin. Jika kegiatan belajar-mengajar mengacu pada peningkatan kecerdasan intelektual, maka kegiatan bimbingan dan konseling di sekolah secara spesifik berorientasi membantu seluruh aspek-aspek perkembangan diri siswa.

Sebagaimana Neviyarni (2009: 75) menyatakan bimbingan dan konseling adalah pelayanan bantuan untuk siswa dengan menciptakan kondisi yang kondusif agar individu dapat berkembang secara wajar sesuai kapasitas dan peluang yang dimilikinya sehingga ia berguna untuk dirinya dan masyarakatnya baik secara perorangan maupun kelompok, serta mampu mandiri dan berkembang secara optimal melalui bidang bimbingan pribadi, bimbingan sosial, bimbingan belajar dan bimbingan karir yang dilakukan dengan berbagai jenis layanan dan kegiatan pendukung berdasarkan norma-norma yang berlaku.

Dalam spektrum pelayanan bimbingan dan konseling dikenal adanya jenis layanan dan kegiatan pendukung. Jenis layanan bimbingan dan konseling adalah layanan orientasi, layanan informasi, layanan penempatan dan penyaluran, layanan penguasaan konten, layanan konseling perorangan layanan bimbingan kelompok, layanan konseling kelompok, layanan konsultasi dan layanan mediasi. Pelayanan bimbingan dan konseling itu perlu dibantu oleh kegiatan pendukung yang terdiri dari pelaksanaan instrumen, himpunan data, konferensi kasus, kunjungan rumah dan alih tangan kasus. Pelaksanaan instrumenlah yang dapat digunakan dalam seluruh spektrum kegiatan pelayanan konseling dari perencanaan sampai dengan penilaian dan pengembangannya. 
Bentuk instrumen itu menurut Prayitno (2006: 6) dapat dipilah mejadi dua macam yaitu instrumen tes dan instrumen non-tes. Instrumen tes jawaban responden atas soal-soal yang ada diperiksa berdasarkan benar salah jawaban yang diberi akar positif dan negatif, sedangkan jawaban instrumen non-tes diperiksa bukan atas benar salahnya. Bukan juga tinggi rendahnya namun mengetahui kondisi sebenarnya.

Setiap individu berpribadi unik oleh sebab itu diperlukan teknik-teknik tertentu dalam memberikan bantuan atau bimbingan dan konseling. Pelaksanaan instrumen non tes dapat digunakan untuk mengungkapkan kondisi siswa. Sebagaimana Tohirin (2007: 208) menyatakan bahwa kondisi dalam diri klien perlu diungkap melalui pelaksanaan instrumen non-tes yang selanjutnya dianalisis, ditafsirkan, disikapi dan digunakan untuk memberikan perlakuan secara tepat kepada klien dalam bentuk layanan bimbingan dan konseling.

Sejalan dengan itu Prayitno (2004: 3) menyatakan pelaksanaan instrumen non-tes dapat digunakan untuk mengungkapkan kondisi siswa dan membantu mengembangkan kondisi yang baik yang ada pada diri siswa. Hasil dari instrumen non-tes dapat digunakan sepenuhnya untuk pengoptimalan layanan yang diberikan kepada siswa. Hasil pelaksanaan instrumen non-tes tersebut dapat mengungkapkan permasalahan apa yang sedang dihadapi siswa saat itu. Kemudian hasilnya instrumen non-tes tersebut juga akan dipergunakan sebagai pedoman dalam pemberian bantuan kepada siswa.

Pendapat siswa juga dipengaruhi oleh kemampuan atau kompetensi guru bimbingan dan konseling dalam melaksanakan instrumen non-tes. Menurut Prayitno (2004: 23) pelaksanaan instrumen non-tes harus direncanakan dan diselenggarakan dengan cermat, dan hati-hati karena itu perlu dilakukan sesuai dengan petunjuk yang dikemukakan yaitu: (1) Guru bimbingan dan konseling harus mempersiapkan/merencanakan pelaksanaan instrumen non-tes, (2) Guru bimbingan dan konseling mengadministrasikan instrumenatasi non-tes dengan menyampaikan maksud dan tujuan pelaksanaan instrumen non-tes, (3) Guru bimbingan dan konseling mengolah dan menyampaikan hasil kepada responden, (4) Guru bimbingan dan konseling menggunakan hasil pelaksanaan instrumen non-tes untuk layanan bimbingan dan konseling.

Fenomena di SMA Negeri 1 Kecamatan Payakumbuh terlihat bahwa guru bimbingan dan konseling kurang mempersiapkan pelaksanaan instrumen non-tes dan ada guru bimbingan dan konseling yang tidak menyampaikan hasil serta kurang menggunakan hasil instrumen non-tes. Kemudian siswa berpendapat pelaksanaan instrumen non-tes belum jelas, kurang bermanfaat, dan kurang memahami tujuan pelaksanaan instrumen non-tes sehingga siswa kurang serius dalam mengisi lembar jawaban dan merasa enggan mengikuti pelaksanaan instrumen non-tes tersebut.

Pelaksanaan instrumen non-tes sangat penting dilakukakan untuk menunjang kegiatan layanan bimbingan dan konseling di sekolah. Pelaksanaan instrumen non-tes sangat bermanfaat bagi siswa. Oleh karena itu hendaknya siswa mengikuti pelaksanaan instrumen non-tes secara sukarela, baik dan benar.

\section{METODOLOGI}

Penelitian ini merupakan penelitian deskriptif yang mendeskripsikan pendapat siswa tentang pelaksanaan instrumen non-tes yang dilakukan oleh guru bimbingan dan konseling. Populasi penelitian meliputi seluruh siswa kelas XI di SMA Negeri 1 Kecamatan Payakumbuh yang terdaftar tahun ajaran 2013-2014 sebanyak 178 orang. Jumlah sampel 61 orang. Instrumen yang digunakan adalah angket dengan dua alternatif jawaban yaitu ya dan tidak. Teknik analisis presentase (A. Muri Yusuf (1997: 349) dengan rumus sebagai berikut:

$$
\mathrm{P}=\frac{f}{n} \times 100
$$

Keterangan:

$P=$ Tingkat persentase jawaban

$\mathrm{f}=$ Frekuensi jawaban atau jumlah skor

$\mathrm{n}=$ Jumlah seluruh responden

Untuk pengklasifikasian jawaban siswa menggunakan klasifikasi yang dikemukakan oleh Suharsimi Arikunto (1996: 244) dan disesuaikan dengan kebutuhan penelitian yaitu: 
Tabel 1

Klasifikasi Pendapat Siswa Tentang Pelaksanaan Instrumen Non-Tes.

\begin{tabular}{|c|l|c|l|}
\hline No & Klasifikasi & Tingkatan & $\begin{array}{l}\text { Penafsiran } \\
\text { Data }\end{array}$ \\
\hline 1 & Sangat Baik & $81 \%-100 \%$ & $\begin{array}{l}\text { Sangat } \\
\text { Terlaksana }\end{array}$ \\
\hline 2 & Baik & $66 \%-80 \%$ & Terlaksana \\
\hline 3 & Kurang Baik & $56 \%-65 \%$ & $\begin{array}{l}\text { Kurang } \\
\text { Terlaksana }\end{array}$ \\
\hline 4 & Tidak Baik & $\mathbf{5 5 \%}$ & $\begin{array}{l}\text { Tidak } \\
\text { Terlaksana }\end{array}$ \\
\hline
\end{tabular}

HASIL

Tabel 2

Rekapitulasi Pendapat Siswa Tentang Pelaksanaan Instrumen Non-Tes.

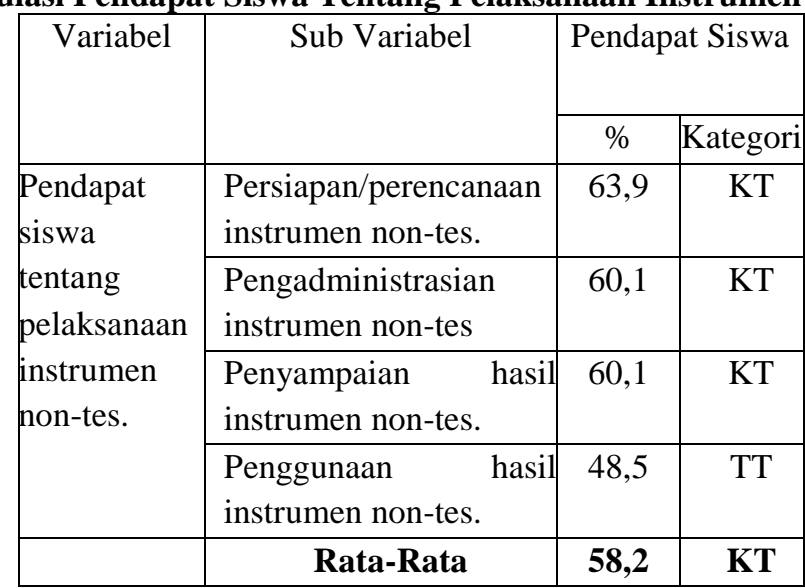

Dari rekapitulasi di atas dapat dilihat pendapat siswa tentang: (1) persiapan/perencanaan instrumen non-tes yaitu 63,9\% dengan kategori kurang terlaksana, (2) pengadministrasian instrumen non-tes yaitu 60,1\% dengan kategori kurang terlaksana, (3) penyampaian hasil instrumen non-tes yaitu 60,1\% dengan kategori kurang terlaksana, dan (4) penggunaan hasil instrumen non-tes yaitu 48,5\% dengan kategori tidak terlaksana.

Secara keseluruhan 58,2\% siswa berpendapat bahwa guru bimbingan dan konseling telah melaksanakan instrumen non-tes berkenaan dengan: persiapan/perencanaan, pengadministrasian, penyampaian hasil dan penggunaan hasil instrumen non-tes yang tergolong kurang terlaksana.

\section{PEMBAHASAN}

Berdasarkan hasil pengolahan data yang telah dilakukan berkenaan dengan pendapat siswa tentang pelaksanaan instrumen non-tes dilihat dari beberapa hal sebagai berikut:

1. Pendapat Siswa Tentang Persiapan/ Perencanaan Pelaksanaan Instrumen Non-Tes yang Dilakukan Oleh Guru Bimbingan dan Konseling.

Dari tabel rekapitulasi dapat dilihat 63,9\% siswa berpendapat bahwa guru bimbingan dan konseling telah mempersiapkan/merencanakan pelaksanaan instrumen non-tes dengan kategori kurang terlaksana.

Pelaksanaan instrumen non-tes akan berjalan dengan baik kalau diawali dengan persiapan yang matang. Sesuai pendapat Helma (2011: 2) menyatakan ada hal penting dalam pelaksanaan instrumen non-tes salah satunya mempersiapkan aspek teknis dan administratif yang di dalamnya termasuk guru bimbingan dan konseling harus menjelaskan kegunaan dari instrumen non-tes tersebut. Menjelaskan manfaat dan kegunaan instrumen non-tes kepada responden dilakukan agar responden merasa mengerjakan instrumen non-tes akan 
ada manfaat dan kegunaan yang akan diperolehnya. Oleh sebab itu memang seharusnya sebelum pengadministrasian instrumen non-tes guru bimbingan dan konseling menjelaskan terlebih dahulu kepada siswa manfaat dan kegunaannya. Sebagaimana Prayitno (2004: 12) juga menjelaskan pengadministrasian instrumen non-tes diawali oleh penjelasan apa, mengapa, dan bagaimana dan untuk apa instrumen non-tes yang dimaksudkan itu dilaksanakan kepada siswa. Dalam hal itu guru bimbingan dan konseling harus mengemukakan pokok, isi, bentuk, tujuan dan kegunaan instrumen bagi responden/siswa.

Persiapan/perencanaan instrumen non-tes sudah terlaksana karena guru bimbingan dan konseling mengkomunikasikan terlebih dahulu kepada pihak terkait kalau guru bimbingan dan konseling akan melaksanakan instrumen non-tes agar siswa juga bisa mempersiapkan segala keperluan untuk mengikuti pelaksanaan instrumen non-tes seperti alat tulis dan yang lainnya. Dengan demikian persiapan/perencanaan pelaksanaan instrumen non-tes akan lebih baik lagi.

\section{Pendapat siswa tentang pengadministrasian instrumen non-tes yang dilakukan oleh guru bimbingan dan konseling.}

Berdasarkan tabel rekapitulasi terlihat $60,1 \%$ siswa berpendapat bahwa guru bimbingan dan konseling telah mengadministrasikan instrumen non-tes kepada siswa dengan kategori kurang terlaksana. Dalam pengadministrasian instrumen non-tes guru bimbingan dan konseling harus menjelaskan kepada siswa tentang cara mengerjakan dan waktu yang disediakan untuk mengerjakan instrumen non-tes. Sebagaimana Helma (2011: 2) menyatakan dalam pengadministrasian instrumen non-tes guru bimbingan dan konseling perlu menjelaskan cara menjawab instrumen non-tes dan memberitahu alokasi waktu yang disediakan untuk mengisi instrumen non-tes.

Kemudian untuk menjelaskan cara mengerjakan instrumen non-tes guru bimbingan dan konseling bisa membacakan petunjuk yang ada pada buku instrumen non-tes yang telah disiapkan sedemikian rupa. Sesuai pendapat Prayitno, dkk (1997: 6) menyatakan petunjuk pengerjaan instrumen non-tes harus dibacakan sepenuhnya oleh guru bimbingan dan konseling agar siswa memahami cara mengerjakannya.

Dengan demikian penjelasan guru bimbingan dan konseling tentang cara mengisi lembar jawaban atau mengerjakan instrumen non-tes sangat diperlukan dalam pengadministrasian instrumen non-tes termasuk memberitahu waktu yang disediakan untuk mengerjakan instrumen non-tes. Penjelasan tentang cara mengerjakan instrumen non-tes agar lebih dipahami siswa dapat dilakukan oleh guru bimbingan dan konseling dengan cara tanya jawab dan penjelasannya ditambah dengan pemberian contoh.

\section{Pendapat siswa tentang penyampain hasil instrumen non-tes yang dilakukan oleh guru bimbingan dan} konseling.

Berdasarkan tabel rekapitulasi terlihat $60,1 \%$ siswa berpendapat bahwa guru bimbingan dan konseling telah menyampaikan hasil instrumen non-tes dengan kategori kurang terlaksana. Menyampaikan hasil instrumen non-tes memerlukan pencermatan tersendiri. Adapun aspek yang dilihat dalam penyampaian hasil instrumen non-tes adalah menyampaikan hasil secara cermat dan hati-hati, menyampaikan hasil dengan format kelompok dan individu serta menerapkan azas kerahasiaan.

Sesuai pendapat Prayitno (2004: 14) data hasil instrumen non-tes dapat disusun dalam kemasan individu ataupun kelompok. Data hasil instrumen tersebut ditafsirkan dan disampaikan dengan pencermatan tersendiri. Hasil instrumen non-tes yang dikemas baik secara kelompok ataupun individu harus dikomunikasikan dengan siswa tanpa kecuali agar pelayanan konseling yang diselenggarakan menjangkau semua individu, khususnya siswa yang menjadi tanggung jawab guru bimbingan dan konseling, namun dalam penyampaian hasil instrumen non-tes azas kerahasiaan harus benar-benar diterapkan, hasil instrumen non-tes tidak boleh dijadikan pembicaraan umum apalagi kalau di dalamnya tersebut nama siswa.

Hasil instrumen non-tes dapat dijadikan topik bahasan terbuka, misalnya disajikan dan didiskusikan dalam kelas namun tidak satu namapun disebut dan tidak satu datapun dikaitkan dengan pribadi tertentu apalagi kalau hasilnya negatif itu akan membuat siswa semakin bermasalah. Oleh sebab itu dalam penyampaian hasil instrumen non-tes guru bimbingan dan konseling harus mengelompokkan terlebih dahulu hasil pengolahan secara kelompok dan individu. Hal yang paling penting dalam penyampaian hasil azas kerahasiaan harus dijaga dengan ketat. 


\section{Pendapat siswa tentang penggunaan hasil instrumen non-tes yang dilakukan oleh guru bimbingan dan} konseling.

Berdasarkan rekapitulasi terlihat $48,5 \%$ siswa berpendapat bahwa guru bimbingan dan konseling telah menggunakan hasil instrumen non-tes dengan kategori tidak terlaksana. Dalam penggunaan instrumen non-tes guru bimbingan dan konseling dapat menggunakan data hasil instrumen non-tes sebagai perencanaan program, penetapan peserta layanan, sebagai isi layanan dan juga tindak lanjut. Sebagaimana Rahma Wira Nita (2011: 2) menyatakan penggunaan hasil instrumen non-tes yaitu sebagai perencanaan program (dalam rangka need assessment), penetapan peserta layanan (klasikal, kelompok, individual), sebagai isi layanan berdasarkan relevensinya, pertimbangan tindak lanjut (khususnya hasil evaluasi seperti penilaian segera, penilaian jangka pendek, dan penilaian jangka panjang).

Kemudian menurut Prayitno (2004: 12) kebutuhan akan informasi oleh siswa dapat diungkap melalui instrumen non-tes yang kemudian hasil instrumen non-tes dapat digunakan langsung maupun tidak langsung dalam pelayanan bimbingan dan konseling. Berdasarkan pendapat Prayitno Contoh penggunaan data hasil instrumen non-tes dalam layanan bimbingan dan konseling dapat digunakan untuk menetapkan informasi yang menjadi isi layanan informasi, calon penerima informasi, dan calon penyaji atau nara sumber yang akan diundang. Dengan demikian informasi yang diberikan guru bimbingan dan konseling kepada siswa harus sesuai dengan apa yang dibutuhkan siswa tersebut. Kebutuhan masing-masing siswa itu dapat dilihat dari hasil instrumen non-tes siswa. Kebutuhan setiap siswa secara menyeluruh biasanya bergerak dalam bidang bimbingan pribadi, bimbingan sosial, bimbingan belajar dan bimbingan karir yang dapat dilihat dari hasil instrumen non-tes tersebut.

Dengan demikian secara keseluruhan pendapat siswa tentang pelaksanaan instrumen non-tes tergolong kurang terlaksana dengan baik. Padahal seharusnya pelaksanaan instrumen non-tes harus dilakukan dengan sebaik mungkin agar benar-benar dapat dipergunakan untuk membantu pelayanan bimbingan dan konseling.

Sesuai pendapat Tohirin (2007: 212) menyatakan untuk keberhasilan pelaksanaan instrumen non-tes perlu dilakukan persiapan/perencanaan instrumen non-tes, pengadministrasian instrumen non-tes, Pengolahan dan pemaknaan jawaban responden, penyampaian hasil instrumen non-tes dan penggunaan hasil instrumen non-tes. Oleh sebab itu untuk keberhasilan pelaksanaan instrumen non-tes semua yang berkenaan dengan pelaksanaan instrumen non-tes harus dilaksanakan sebagaimana mestinya.

\section{KESIMPULAN DAN SARAN}

Hasil penelitian menunjukkan bahwa pendapat siswa tentang pelaksanaan instrumen non-tes dalam hal: (1) persiapan/perencanaan sudah terlaksana dengan baik, sedangkan (2) pengadministrasian, (3) penyampaian hasil, dan (4) penggunaan hasil instrumen non-tes kurang terlaksana dengan baik.

Berdasarkan hasil temuan tersebut peneliti menyarankan agar guru bimbingan dan konseling dapat meningkatkan pelaksanaan instrumen non-tes terutama dalam hal pengadministrasian, penyampaian hasil dan penggunaan hasil instrumen non-tes. Kepala sekolah diharapkan memberikan perhatian terhadap proses kegiatan bimbingan dan konseling terutama dalam pelaksanaan instrumen non-tes dengan memberikan fasilitas yang lebih lengkap untuk menunjang pelaksanaan kegiatan tersebut. Diharapkan juga kepada pimpinan dan dosen jurusan bimbingan dan konseling agar merancang suatu kegiatan pelatihan pelaksanaan instrumen non-tes untuk meningkatkan wawasan mahasiswa dan kualitas guru bimbingan dan konseling.

\section{DAFTAR RUJUKAN}

A. Muri Yusuf. 1997. Statistik Pendidikan. Padang: Ikip Padang.

Helma. 2011. Sosok Utuh Kompetensi Profesional Konselor. Padang: STKIP PGRI

Prayitno, dkk. 1997. Pedoman Alat Ungkap Masalah (AUM PTSDL Format-2:Siswa SLTA). Padang: FIP IKIP.

Prayitno. 2004. L.1-L.9 Jurusan Bimbingan dan Konseling. Padang: FIP UNP.

Prayitno. 2006. P.1-P.6 Jurusan Bimbingan dan Konseling. Padang: FIP UNP. 
Rahma Wira Nita. 2011. Penyusunan Pelaksanaan Pengelolaan dan Evaluasi Program PPLBK Sekolah. Padang: STKIP PGRI.

Suharsimi Aikunto. 1996. Metodologi Penelitian. Jakarta: Rineka Cipta.

Tohirin. 2007. Bimbingan dan Konseling di Sekolah dan Madrasah. Jakarta: PT Raja Grafindo Persada. 